\title{
Cathedral outreach: student-led workshops for school curriculum enhancement in non-traditional environments
}

Matthew Posner, Alexander Jantzen, Lieke van Putten, Andrea Ravagli, Andrei Donko, et al.

Matthew T. Posner, Alexander Jantzen, Lieke D. van Putten, Andrea Ravagli, Andrei L. Donko, Nathan Soper, Nicholas H. L. Wong, Pearl V. John, "Cathedral outreach: student-led workshops for school curriculum enhancement in non-traditional environments," Proc. SPIE 10452, 14th Conference on Education and Training in Optics and Photonics: ETOP 2017, 1045207 (16 August 2017); doi: 10.1117/12.2266451

EDEent: 14th Conference on Education and Training in Optics and Photonics, ETOP 2017, 2017, Hangzhou, China 


\title{
Cathedral outreach: student-led workshops for school curriculum enhancement in non-traditional environments
}

\author{
Matthew T. Posner ${ }^{\mathrm{a},}{ }^{,}$, Alexander Jantzen ${ }^{\mathrm{a},},{ }^{*}$, Lieke D. van Putten ${ }^{\mathrm{a}}$, Andrea Ravagli ${ }^{\mathrm{a}}$, Andrei L. \\ Donko ${ }^{\mathrm{a}}$, Nathan Soper ${ }^{\mathrm{a}}$, Nicholas H. L. Wong ${ }^{\mathrm{a}}$, and Pearl V. John ${ }^{\mathrm{b}}$ \\ ${ }^{a}$ Optoelectronics Research Centre, University of Southampton, Southampton, SO17 1BJ, UK. \\ ${ }^{\mathrm{b}}$ Physics and Astronomy, University of Southampton, Southampton, SO17 1BJ, UK. \\ ${ }^{*}$ These authors contributed equally to this work.
}

\begin{abstract}
Universities in the United Kingdom have been driven to work with a larger pool of potential students than just the more traditional student (middle-class white male), in order to tackle the widely-accepted skills-shortage in the fields of science, technology, engineering and mathematics (STEM), whilst honoring their commitment to fair access to higher education. Student-led outreach programs have contributed significantly to this drive. Two such programs run by postgraduate students at the University of Southampton are the Lightwave Roadshow and Southampton Accelerate!, which focus on photonics and particle physics, respectively. The program ambassadors have developed activities to enhance areas of the national curriculum through presenting fundamental physical sciences and their applications to optics and photonics research. The activities have benefited significantly from investment from international organizations, such as SPIE, OSA and the IEEE Photonics Society, and UK research councils, in conjunction with university recruitment and outreach strategies. New partnerships have been formed to expand outreach programs to work in non-traditional environments to challenge stereotypes of scientists. This paper presents two case studies of collaboration with education learning centers at Salisbury Cathedral and Winchester Cathedral. The paper outlines workshops and shows developed for pupils aged 6-14 years (UK key stages 2-4) on the electromagnetic spectrum, particle physics, telecommunications and the human eye using a combination of readily obtainable items, hand-built kits and elements from the EYEST Photonics Explorer kit. The activities are interactive to stimulate learning through active participation, complement the UK national curriculum and link the themes of science with the non-traditional setting of a cathedral. We present methods to evaluate the impact of the activity and tools to obtain qualitative feedback for continual program improvement. We also share lessons learned to assist educators emulating this format of engagement, and provide ideas and inspiration of outreach activities for student chapters to carry out.
\end{abstract}

Keywords: Optics education, Physics outreach, Science, culture and religion, Public engagement with research, Widening participation, Student chapters, STEM

\section{INTRODUCTION}

International professional associations, regional social-economic factors and local research institutions all contribute to the development of a framework to engage with a larger pool of individuals to address a recognized skills shortage in the discipline areas of science, technology, engineering and mathematics (STEM). ${ }^{1,2}$ Studentled education and engagement endeavors play a significant role in increasing the reach of education programs through direct interaction with local communities. Through two case studies of working in the atypical setting of cathedrals, we present motivations and demonstrate benefits for taking outreach to non-traditional areas of the community. We set out the context, actors and motivations for these activities in $\S 2$, and present the aims and objectives of this project in $\S 3$. $\S 4$ provides practical considerations for the delivery of workshops and shows, and offers the reader examples of activities and educational tools developed for this work that can be transferred to their local community-driven programs. We describe methods of incorporating the evaluation of the activity as

Further author information: (Send correspondence to M. T. P.)

M. T. P.: E-mail: m.posner@soton.ac.uk, Telephone: +44 (0)2380 592959

14th Conference on Education and Training in Optics and Photonics: ETOP 2017, edited by Xu Liu,

Xi-Cheng Zhang, Proc. of SPIE Vol. 10452, 1045207 · (C) 2017 ICO, IEEE, OSA, SPIE

CCC code: $0277-786 X / 17 / \$ 18 \cdot$ doi: $10.1117 / 12.2266451$

Proc. of SPIE Vol. 10452 1045207-1 
part of the delivery, and in $\S 5$ we present evidence of the success of the activities. We compare our results with those from identical workshops run in traditional environments to highlight benefits and further motivation to pursue such ventures. We conclude the report by offering some of the lessons learned and suggestions for future work in $\S 6$.

\section{BACKGROUND}

The following section outlines the main drivers for education and engagement programs reaching out to new areas of the community to increase the pool of potential students gaining access to higher education. We will introduce two student-led programs at the University of Southampton, UK, that contribute to this drive through different formats of delivery and discuss motivations to utilize these initiatives to engage with new audiences in non-traditional environments.

\subsection{Widening Participation}

The UK suffers from a well-documented skills shortage of students in physics and photonics in higher education, with intake being hindered by multiple barriers of entry (gender, socio-economic, ethnicity, public perception, specialist teaching, etc.) into STEM-related subjects at higher education. ${ }^{1,2}$ A rich combination of socio-economic drivers are leading funding organizations and research institutes to diversify their portfolio of activities and engage with school pupils and the public to change attitudes towards higher education and research ${ }^{3}$ and to uphold funding requirements. ${ }^{4}$ Funding opportunities have consequently arisen through international organizations (OSA, SPIE, IEEE Photonics Society, etc.), research councils' public engagement with research commitments (UK Engineering and Physical Sciences Research Councils, UK Science, Technology Facilities Council, etc.) and also at an institutional level. We direct the reader towards a recent report for further discussion on the drivers of this culture change ${ }^{5}$ and also funding opportunities that can benefit community programs, in particular for student-led community education programs. ${ }^{6}$ The quality of the engagement activity from an educational and social perspective is an important factor, and there are growing requirements to provide measurable evidence of the impact of the activity: we will present in $\S 5$ examples of results that can be employed for reporting purposes when working with pupils. One strategy to gain access to wider areas of the local community is to diversify the offerings of engagement and education actions with different types of events; we present in the following subsections outreach and public engagement programs offered by the University of Southampton involving workshops and shows.

\subsection{The Lightwave Roadshow}

The Lightwave Roadshow is an optics and photonics outreach education and public engagement program run by postgraduate research students (PGRs) through the University of Southampton's (UoS) Optics and Photonics Society (OPSoc). The program was established in 1998 by PGRs in the Optoelectronics Research Center (ORC) at UoS as a traveling roadshow for young children in pre-school, primary school, youth clubs and science fairs. ${ }^{7,8}$ More recently, the program has expanded its portfolio of activities to work with older pupils in middle and high school in school-university partnerships, as well as with the general public. ${ }^{5}$

With the increasing demand for activities and a growing number of partners, the Lightwave Roadshow has formalized its educational offering with lesson plans designed to enrich the UK National Curriculum. The program offers classes based around tabletop workshops with experiments and demonstrations on optical sciences and their applications to research and everyday life. Typical classes will last 45 minutes to 1 hour, and will be delivered by 3-4 PGR 'Lightwave Ambassadors', to groups of 30-40 pupils. The classes can be repeated multiple times per day and using this workshop-based format of delivery, the program has engaged with over 2,500 school pupils in the South of England since 2013 in the traditional settings of school classes or fairs for schools. Further details on using workshops in the context of this case study are discussed in $\S 4$. 


\subsection{Southampton Accelerate! Roadshow}

Accelerate! was originally developed at the University of Oxford as a demonstration lecture about particle physics. The lecture was considered a success as it managed to make an otherwise hard to learn subject fun and engaging. The resources and lecture format were made available online ${ }^{9}$ and the lecture has since been adapted by PGRs from the UoS into an interactive roadshow.

Southampton Accelerate! is an outreach program run by PGRs from both the UoS ORC and the Physics and Astronomy (PA) departments. The show was adapted in 2013 and since has engaged with over 2,000 school pupils and members of the public. A typical Accelerate! performance can cater for an audience of a few tens to several hundred people and takes approximately 50 minutes from start to end. The learning objectives are mainly aimed at pupils in Key Stages 3 and 4 (aged 11 to 16 years) due to the complex nature of the topic, although enjoyment can be found for all audience members of any age watching the experiments and taking part in the interactive elements of the show. An adaption from the original Oxford version that has been made is to include information on careers in physics with a focus on the research undertaken by the PGRs presenting.

\subsection{Motivation for Outreach in Non-Traditional Environments}

UK universities make substantial efforts to reach out to students from non-traditional backgrounds (i.e. from certain ethnic and socio-economic groups) to encourage them to consider studying at university. The most effective ways to recruit students have generally been to get potential students to visit university campuses. ${ }^{10}$ This approach has not, however, changed the gender make-up of the recruits: there remains a lack of women studying physics and photonics, and a general shortage of students in STEM subjects persist. Female students in particular do not aspire to go into careers in STEM subjects, particularly physics, despite enjoying and/or being good at science. ${ }^{11}$ The issue relates to "Science Capital" 12 i.e. whether friends and family of students are familiar with opportunities available in STEM Careers. Traditional approaches of working in schools, universities and science festivals will not reach out to potential new students without considering the importance of this aspect.

Outreach in non-traditional environments can enable universities to engage with otherwise hard-to-reach individuals and new audiences. New venues can provide novel approaches to introducing audiences to STEM activities and careers of which they were previously unaware. Operating in non-traditional environments requires collaborating with external partners to help facilitate the events. This collaborative outreach effort is of interest to both parties as it offers routes to expand the visibility and engagement initiatives for everyone involved. Examples of activities in non-traditional environments include: the embedding of photonics outreach activities in city light shows and festivals, ${ }^{13}$ dancing experiments, ${ }^{14}$ virtual environments (smartphone applications, websites, etc.) ${ }^{15}$ and engaging the public with photonics research at music festivals and at garden shows. ${ }^{16}$ The UoS was approached by Salisbury and Winchester Cathedrals to take part in their outreach activities. A partnership was formed between the cathedrals and the Lightwave and Southampton Accelerate! programs to carry out activities, which is described herein.

To the best of our knowledge, no study has been conducted between comparing the impact of outreach activities run in "traditional" environments (classrooms, science fairs, museums, etc.) and "non-traditional" environment. This comparison is made in $\S 5$ with data obtained from 569 participants in both non-traditional and traditional environments. Next, we present the aims and objectives of the projects.

\section{AIMS AND OBJECTIVES}

\subsection{Educational Objectives}

The overarching aim of the projects is to help pupils to work with real scientists in spectacular medieval buildings, to carry out practical experiments that are all linked to the cathedral itself. The activities developed incorporates areas of the UK National Curriculum in science as described in Table 1.

Further educational items can be included in the activity that do not form part of the national curriculum, but which emphasize experimental investigation and are relevant to their everyday lives. For instance, telecommunications does not form part of the National Curriculum until Key Stage 5 (ages 16-18 years), however its applications for research and in everyday life are an important pillar of modern society. The process of learning is also emotional, and offering opportunities to form opinions and enjoyment are vital in achieving the desired outcomes. 
Table 1: Activity learning objectives and links to national curriculum and cathedrals.

\begin{tabular}{|c|c|c|}
\hline Activity learning objectives & National Curriculum elements & Relevance to cathedrals \\
\hline $\begin{array}{c}\text { Recognize the elements of the } \\
\text { human eye. }\end{array}$ & $\begin{array}{c}\text { Explain that we see things because } \\
\text { light travels from light sources or } \\
\text { objects and then to our eyes. }\end{array}$ & $\begin{array}{c}\text { Light is essential in cathedrals } \\
\text { to see stories. }\end{array}$ \\
\hline $\begin{array}{c}\text { Name the primary colors of } \\
\text { light. }\end{array}$ & $\begin{array}{c}\text { Experience a range of light-based } \\
\text { phenomena including colored filters } \\
\text { and rainbows. }\end{array}$ & $\begin{array}{c}\text { Explain how stained glass } \\
\text { works. }\end{array}$ \\
\hline $\begin{array}{c}\text { Participate in and/or observe a } \\
\text { series of experiments. }\end{array}$ & $\begin{array}{c}\text { Experience and interact with } \\
\text { non-mechanical forces. }\end{array}$ & Creation of the universe. \\
\hline $\begin{array}{c}\text { Enjoyment of interactive } \\
\text { demonstrations. }\end{array}$ & $\begin{array}{c}\text { Emotions towards science through } \\
\text { experimentation. }\end{array}$ & Showcase non-conflicting views. \\
\hline
\end{tabular}

\subsection{Social Impact}

Second to the educational objectives is the impact on perceptions between religion and science as well as the consequence on the community as a whole. The authors' approach is aimed at generating mutual understanding and creating discussion. The engagement with non-traditional audiences offers the potential for a greater change of attitude towards people and careers in STEM. This change is facilitated by providing role models from diverse background (for e.g. ethnicity, gender), thus challenging stereotypes of scientists and engineers. This is of value to both the outreach provider and event hosts. For the Cathedrals, the aim is to appear more open, understanding and welcoming to the younger generations. Although not explicitly mentioned by the collaborators, it is clear that Church of England participation is dwindling when observing the population attendance over the past half century (Figure 1) ${ }^{19}$ For the authors, the value lies in interacting with an otherwise hard to reach audience and is in line with the goal of widening participation. It was believed by the external partners that, that by involving more STEM based activities, a growth in their participation numbers for youths would increase. Furthermore, it was also hoped that the students would view cathedrals as being a space for community rather than just religious practice.

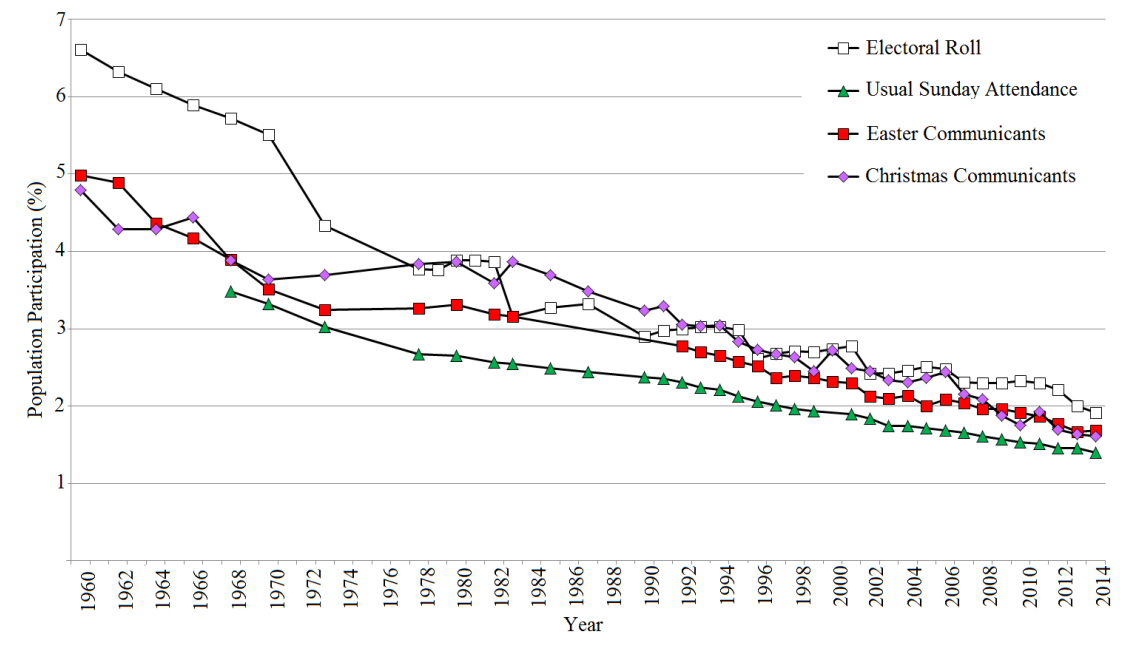

Figure 1: A steady decline in Church of England participation has been reported. This phenomenon has been attributed to a shrinking interest amongst the younger population. Figure adapted from Ref. ${ }^{19}$ 


\section{DELIVERY}

Lightwave and Southampton Accelerate! worked in collaboration with educational and youth leaders from the Winchester and Salisbury cathedrals. The programs delivered workshops and shows to school pupils aged 9-14 years inside the cathedrals themselves (Figure 2) to teach topics and develop skills relevant to the appropriate Key Stages of the UK Science National Curriculum. The activities also provided the pupils with the opportunity to gain an understanding of some of the science applications in the working world and their relevance to cathedrals. This section describes practical considerations for the delivery of workshop and shows in cathedrals, and we present alongside these discussions activities specifically developed to integrate the learning objectives with the cathedral itself. We introduce methods for evaluating the quality of the delivery in terms of educational accomplishment, enjoyment and change of behavior.

We note that practical considerations for general outreach activities are applicable to working in nontraditional environments to ensure the safety of the pupils, teachers, demonstrators and other individuals present in and around venues. Preparation should ensure that the equipment is safe for use (controlled hazards for electrical, sharps, etc.) and that demonstrators are trained in the setup and use of the equipment. Where specialized equipment is used (lasers, liquid nitrogen, hydrogen, etc.) extra controls should be put in place.

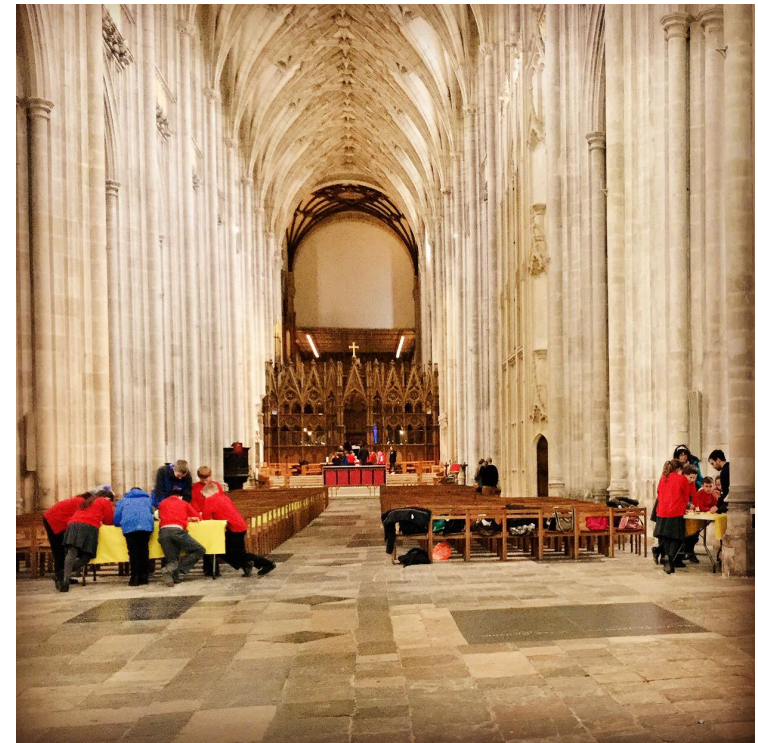

(a)

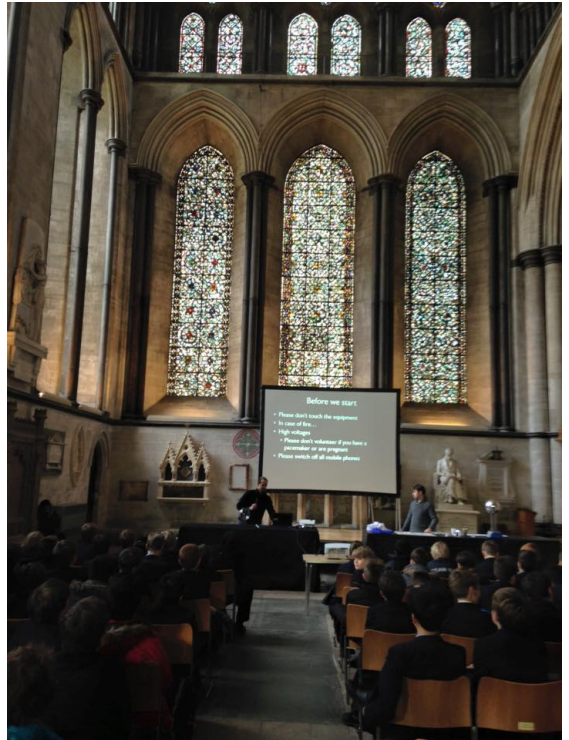

(b)

Figure 2: The University of Southampton's Lightwave and Accelerate! Roadshows took part in education community events in cathedrals. (a) Tabletop workshops at the Winchester Cathedral Primary Science Festival. (b) Shows at the Salisbury Cathedral in support of "God and the Almighty Big Bang" education day.

\subsection{Workshops: Lightwave at Winchester Cathedral}

The Lightwave Roadshow workshop was run as part of the 2016 Winchester Cathedral Primary Science Festival, which aimed to introduce UK Year 6 pupils (aged 9-10 years) to light sciences and their relevance to the architecture of the cathedral. The workshop was structured around three main activities on the electromagnetic spectrum, the human eye and telecommunications. These activities linked educational learning objectives with the spectacular medieval building where the workshop was located (Table 1). The workshop duration was 45 minutes and six sessions were run over a two-day period with youths from two local schools. Approximately 15 youths attended each session, and they were split up into three sub-groups to rotate around the demonstrator tables shown in Figure 3. The small group sizes meant that we could monitor the use of the equipment and experiments; this also allowed the demonstrators to observe that all the youths all had the chance to experiment and engage with the activity. The level of enjoyment was recorded at the end of the session and feedback and is presented in $\S 5$. 


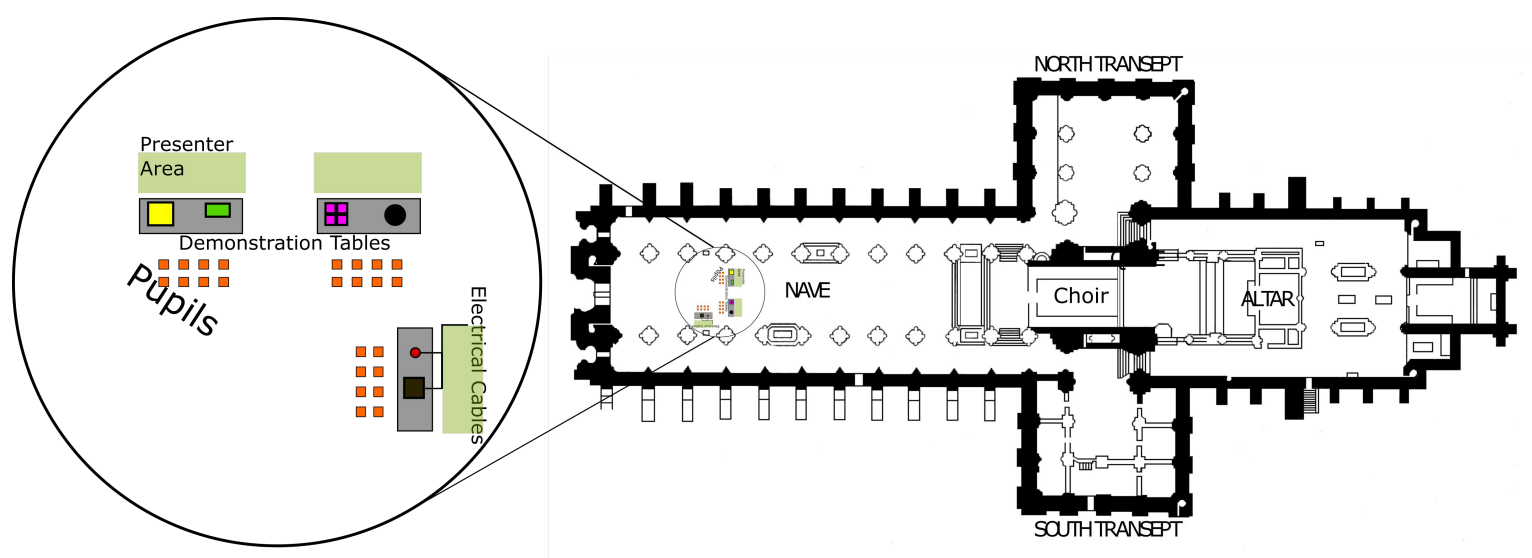

Figure 3: Three sets of hands-on activities on the topics of the electromagnetic spectrum, the human eye and telecommunications were presented in the heart of the nave of Winchester Cathedral. The equipment indicated by the shapes on the tables is a collection of experiments and demonstrations suitable for youths aged 9-11 years. Each group is split into 3 sub-groups that explore the topics for approximately 10 minutes and rotate around the tables.

A key part of the workshop was to provide activities tying into the theme that light is used to tell stories. We developed a new activity to describe the operation and components of the human eye with a worksheet and an interactive demonstration. The activity features a hand-build kit, for which the different components are shown in Figure 4a. Light is shone through an object towards a human eye model. It passes through the object, and into the eye through the cornea, iris and a liquid lens to form an image on the retina at the back of the eye. The cornea and iris elements included in the setup are for youths to recognize the elements of the eye. The liquid lens is a plastic membrane connected to a syringe and hose to fill the lens; this is used to illustrate that a liquid lens is required in the eye to see objects. The image formed is upside down (see Figure $4 \mathrm{~b}$ ) for the youths to experience the effect of using lenses in systems. An adjustable strap on the top of the eye can change the depth of the retina. This is used to explain sight problems that develop (such as short and long-sightedness), and the youths can experiment with lenses to make corrections to the image.

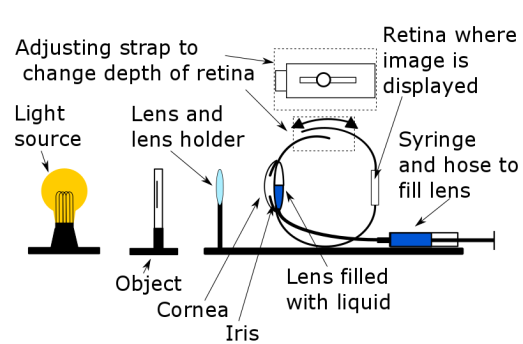

(a)

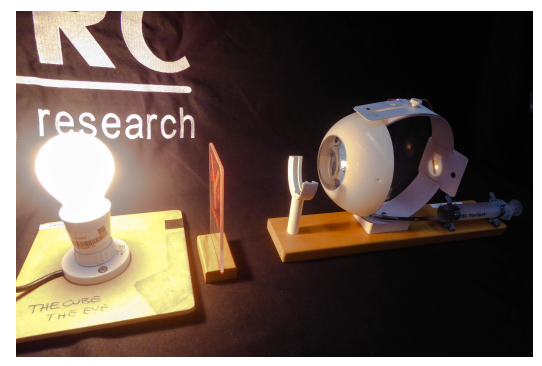

(b)

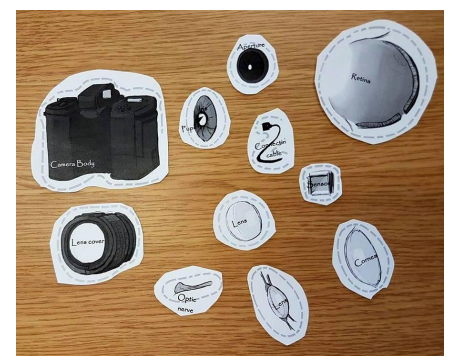

(c)

Figure 4: "Light is used to tell stories in cathedrals" - development of a table-top workshop module for pupils on the components and operation of the human eye. (a) Schematic diagram of the human eye model. (b) The human eye model in operation, showing how an image is formed upside down on the retina. (c) EYEST Photonics Explorer kit worksheet to recognize the different parts of the eye and compare them to a camera.

We provide accompanying handouts for students to make use of their observations and re-create on paper how the human eye is formed. This serves the purpose of introducing the pupils to new technical vocabulary. The handout also includes the functional parts of the camera and links these to how the eye is formed and operates. This is to give the pupils an appreciation for the application of optics as relevant to their everyday lives (vision, photography). The worksheets are based on the EYEST Photonics Explorer kit (http://www.eyest. 
eu/STEM-Programs/Photonics-Explorer) and a set of the handouts is shown in (Figure 4c). The workshop also has two additional table-top activities and the reader is referred to supporting reports for details on the kit relating to the the electromagnetic spectrum ${ }^{5}$ and telecommunications. ${ }^{20}$

\subsection{Shows: Southampton Accelerate! at Salisbury Cathedral}

Southampton Accelerate! was invited by Salisbury Cathedral Education Center to participate in their theme-day: "God and the Almighty Big Bang". The show was selected to focus on presenting the events that led to the creation of the universe with the Big Bang. Three other workshops took place alongside Accelerate! and the pupils were rotated between them in 4 groups. Approximately 50 pupils attended each performance and three shows were delivered over two days to $\sim 150$ UK Year 7-8 (aged 11-13 years) pupils from local grammar schools. The show was placed in the north transept of the cathedral to accommodate for the large group size, as shown in Figure 5.

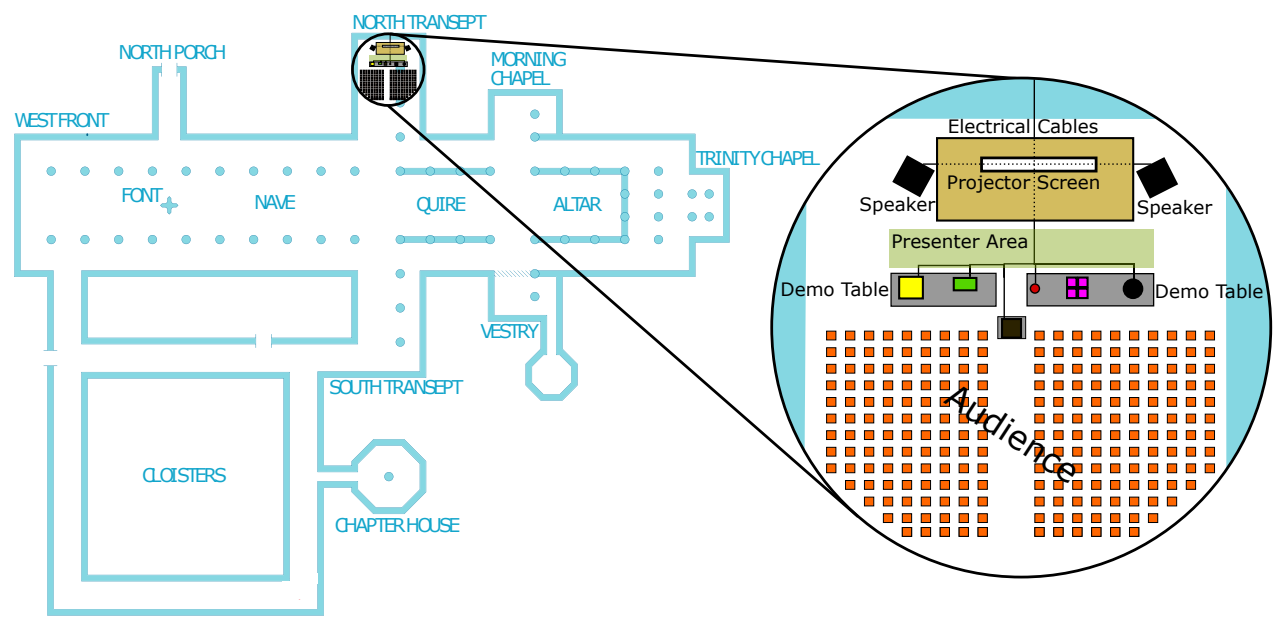

Figure 5: Situated in the North Transept, Southampton Accelerate! presented at Salisbury Cathedral over two days to three different groups of pupils with the setup as shown. The equipment items are color-coded shapes: yellow is the CRT-TV, green is the laptop, brown is the projector, red is the plasma ball, purple cubes are heat mats for liquid nitrogen and the black sphere is the Van der Graaf generator.

The show was presented by three PGRs using a series of slides as visual aids for the information presented and experimental demonstrations taking place every 5 minutes. The first demonstration uses a hydrogen balloon and a candle to explode it. This is intended to showcase the source of particles used for particle collisions and grabs the attention of the audience. It should be noted that, this experiment was excluded from the show in the cathedral due to the irreplaceable value of some of the glass work in the cathedral windows (Figure 6a). To show how particles can be stripped of their electrons, a Van der Graaf generator is used to create lightning and electrify a volunteer with confetti in their hand. Upon opening their hand, the small paper cutouts will fly into the air showing how charged objects can be accelerated. The third demonstration involves a plasma ball and a fluorescent tube held by a member of the audience. As the tube moves closer to the ball, at a certain point, the tube will light up without making contact and exhibits action at a distance. Particle control is demonstrated with the use of a cathode ray tube television and a neodymium magnet to distort the image and show the emanating magnetic field lines. The influence of high current flowing through materials is shown by igniting steel wool with a battery. A focal point of the show is the use of liquid nitrogen to freeze flowers and make a high temperature superconductor levitate through the Meissner effect. As the second, third, fourth and Meissner effect demonstration are hard to observe at a distance, a camera and projector is used to provide a view. The final interactive demonstration uses the help of the entire audience to recreate particle collisions with giant beach balls and compares the energy levels between a fixed target collision and a center of mass collision. At least 10 giant beach balls are used and are required to be inflated well in advance of the show in order to 


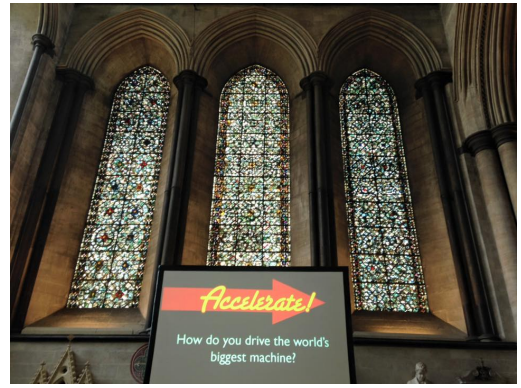

(a)
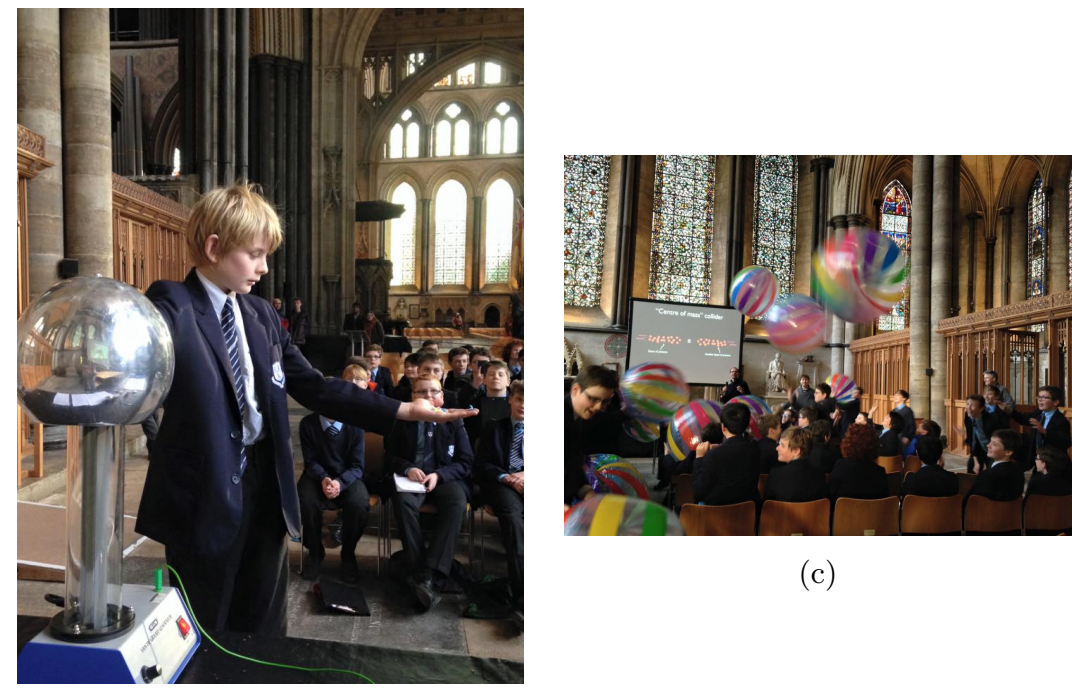

(c)

(b)

Figure 6: To explore how CERN are recreating events similar to those at the beginning of the universe, a series of interactive experiments and demonstrations are made by the Southampton Accelerate! show in Salisbury Cathedral. (a) Presenting screen at Salisbury Cathedral. (b) Volunteers pupils are invited to participate in experiments. (c) Audience demonstrates particle collision methods.

minimize disruption of simultaneous church services. The final conclusion presented to the students informs them about career aspects and opportunities within STEM subjects. This collection of interactive demonstrations and experiments, combined with a dynamic presentation style, constitute the Southampton Accelerate! show.

Utilities available should be checked in advance as Accelerate! requires electrical supplies to run several of the demonstrations. Despite the cathedral being 800 years old, renovation has seen to this requirement as well as the aid of a speaker system that allowed for clear communication to all members of the audience. Without audio aid, due to the size of the cathedral, it can be challenging for the audience to hear at the back. Prior to the event, fragile items were relocated from the area surrounding the show to avoid any potential damage caused by the demonstrations. This was in particular to avoid any stray giant beach balls (Figure 6c) knocking things over. The open nature of the location allows for demonstrations with volunteers to be seen by all of the audience as long as they are elevated slightly. In the case of the Van der Graaf experiment (Figure 6b), the stool used to insulate the volunteer serves this as a dual purpose. Time keeping was to be kept strictly in order to respect and minimize the disruption of the hourly prayers. This meant that any feedback session or question time was kept short. We discuss the evaluation component of the shows and workshops in the following section.

\subsection{Quiz-based Evaluation}

An essential part of the shows and workshop is to evaluate the impact of the activity conducted. Both Lightwave and Accelerate! resort to quiz-based evaluation methods. Quizzes provide a method to measure reach, assess demographics, record the assimilation of knowledge, assess enjoyment and measure the change of attitude as a result of the interaction. The quiz must be designed with these objectives in mind and used as a tool to conclude the activity. We note that if organizing activities as part of a larger event, then other quizzes may be distributed by other partners. Adequate discussion and preparation to make the quizzes event-specific and suitable for the task should be considered in the design of the quiz, or the results can be skewed by misinterpretation of the context of the question or other activities happening in parallel.

To facilitate the feedback, both programs have incorporated two methods of evaluation to evaluate performance, namely paper-based and online quizzes. The online quiz uses a smartphone based solution such as Kahoot (https://getkahoot.com/). Kahoot is a quiz and survey manager that people can participate in by logging in on a website with their phones. This method works by having the presenter log into their account and chose the 
quiz to use. The presenter will then be prompted to a web page that can be put into full screen and shown to the audience via a projector. A code will be displayed that the participants will need to enter into the website along with a nickname. Once the organizer deems that sufficient people have joined, the quiz can be started. A multiple choice question will be shown on the screen with two to four answers and each is marked by a unique colored symbol. These color symbols will appear on the participants phones and they can tap the symbol they believe corresponds to the correct answer. This can be turned into a game with points being awarded for correct answers and the speed at which they are selected. Running an introductory quiz prior to the event to familiarize the participants allows subsequent quizzes to be done more rapidly. This would typically be done by providing them with the sign in details for a free Wi-Fi connection offered by the host. Without the provision of free internet access, the response rate will be heavily diminished. An advantage of providing the participants with $\mathrm{Wi}-\mathrm{Fi}$ is their willingness to engage with their mobile devices and post on social media about it. Additional advantages of doing an initial introductory quiz is that it allows for the audiences perception to be gauged prior to the interaction. This provides a more accurate representation of their feelings towards the topic prior to the event compared to simply asking them explicitly post event. The identical question can then be asked again at the end of the show and behavioral changes can be noted from this.

Each method has its own pros and cons. Online-based methods are more interactive and engaging as the participants utilize their smartphones. A significant downside to this is the requirement of internet access. As this was difficult to obtain for all attendees in the cathedral, for the case of the two cases presented here, paper versions were used in both instances. A summary of the objectives, methods, and pros and cons of quiz-based evaluation methods is presented in Figure 7.

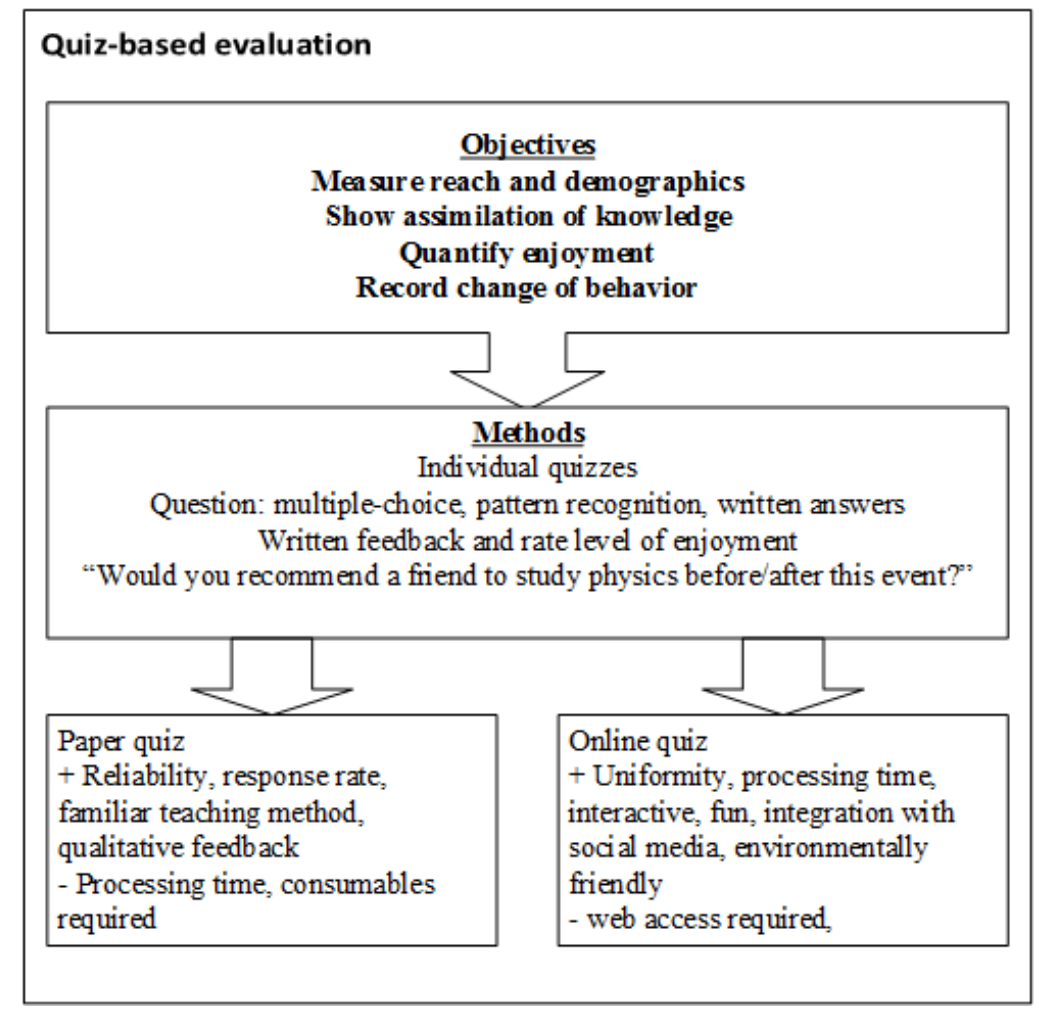

Figure 7: Objectives, implementations and pros and cons of different quiz-based evaluation methods.

\section{RESULTS}

Over the course of these cathedral events, we collected quizzes from 190 (89 workshops and 101 show attendees) pupils aged 9-13 years old and we present evidence of the success. We compare these results with feedback from 
quizzes obtained from 379 participants (222 workshops and 157 show attendees) in more traditional engagement platforms such as festivals, school STEM days and at science center fairs.

\subsection{Evidence of Success}

The data collected from the quizzes completed at cathedral events shows that the activities were very well received by the pupils, with a high overall rating of 9.5/10 for levels of enjoyment (Figure 8a). Written feedback indicated that pupils particularly enjoyed practical activities (Figure 8b). Every pupil indicated that they had learned something new, and we have collected good evidence of learning through the knowledge-based questions on the quizzes. The average score was 8.7/10 with ratio of correct to incorrect responses shown in Figure 9. For the primary school workshops, there was an equal balance of male and female students. For the shows with older pupils, the ratio of female to male pupil in attendance dropped considerably.

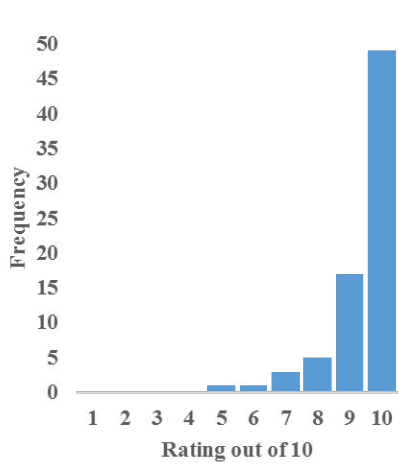

(a)

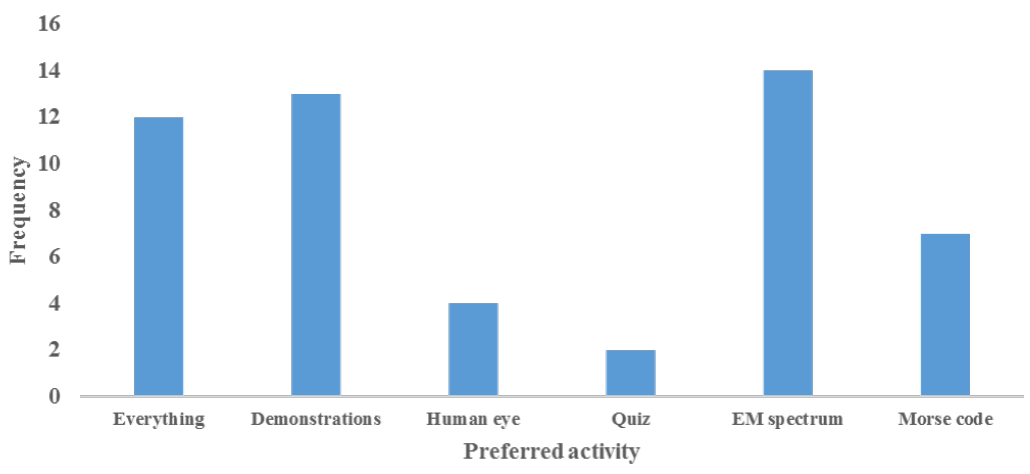

(b)

Figure 8: Evaluation in terms of enjoyment and assimilation of knowledge. (a) Following the workshop the students were asked to rate their enjoyment of the activity on a scale from 1 to 10 with higher being greater enjoyment. Surveys completed: 89. (b) Students were asked to indicate which part of the workshop they enjoyed and found the most engaging. Responses recorded: 52 .

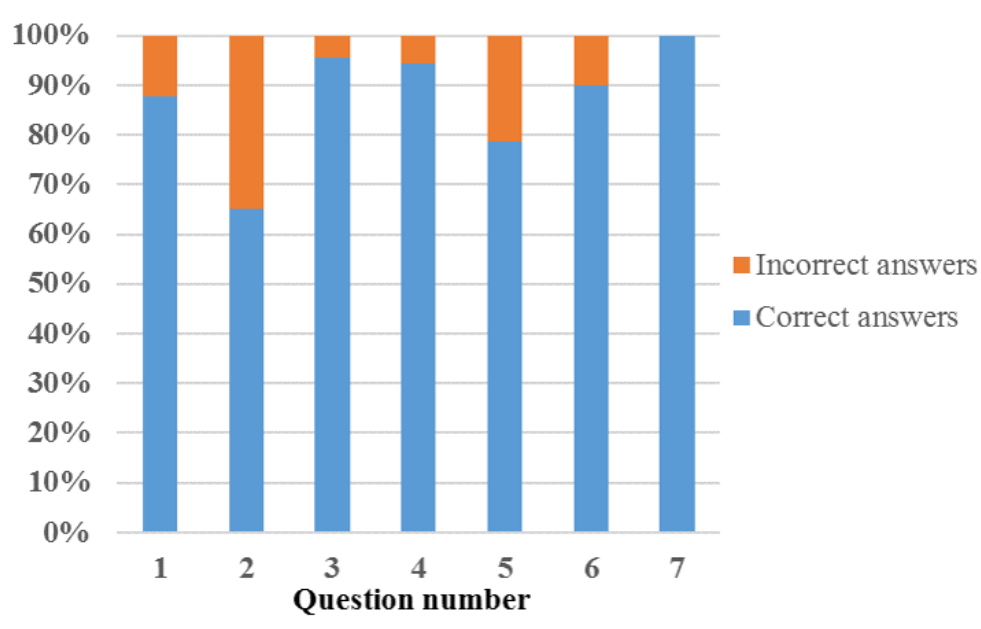

\author{
Questions \\ 1: Identify OSA \\ 100 celebrations. \\ 2: Identify \\ primary colours of \\ 3-5: Human eye: \\ true or false. \\ 6: Recognise \\ human eye retina. \\ 7: Recognise SOS \\ in Morse code.
}

light.

Figure 9: Strong assimilation of knowledge with the distribution of answers showing that pupils found that identification of the primary colors of light (red, green, blue) challenging, although the average score remained high at 8.7 out of 10 .

Educational objectives were met with good signs of learning and enjoyment. We observed that perception towards the relationship between science and religion was also questioned by the students during post-activity 
Q\&A. At the end of the Accelerate! show the students were asked in a multiple choice question how they felt about particle physics, before and after the activity. A total of 101 participants completed the survey and the distribution can be seen in Figure 10. Nearly half the audience was unsure of how they felt or believed that particle physics was useless prior to the activity. This group dropped to below $10 \%$ after the show. This showed the participants were receptive to change and that the activity had a positive impact upon them. No long term follow up was made and so only immediate impact was observed.
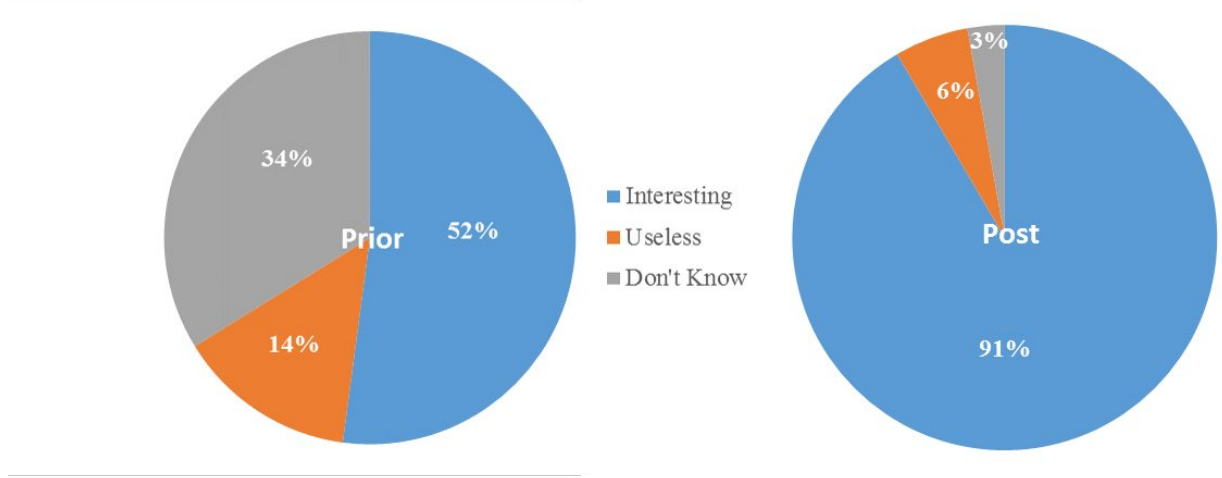

Figure 10: Students in a non-traditional setting were asked for their perception on particle physics, before and after the Southampton Accelerate! show in Salisbury Cathedral. Responses recorded: 101.

\subsection{Comparison to Traditional Environments}

The Lightwave and Southampton Accelerate! roadshows both pursue science outreach activities in traditional environments, namely on university campuses, in schools and at science fairs. The online and paper-based evaluation methods ( $\$ 4.3)$ were used to obtain feedback from 379 participants (222 workshops and 157 show attendees), and here we compare the measured impact in terms of educational benefit, enjoyment level and change of attitude between traditional and non-traditional environments.

The average test score is 7.9/10 in classes, compared to 8.7/10 in cathedrals. Both indicate good assimilation of knowledge overall. The results obtained from working in non-traditional environments are higher, indicating that the pupils may have engaged more thoroughly in the activities due to the special nature of the event. The overall event rating for enjoyment is 8.9/10 in traditional environments, compared to $9.5 / 10$ for our work in cathedrals. Pupils indicated that they enjoyed the class, particularly demonstrations. We note that some pupils in cathedrals indicated that they enjoyed the quiz whilst no pupils in classrooms enjoyed these, but overall the levels of enjoyment of activities do not differ significantly between traditional and non-traditional environments. A summary of these results is shown in Figure 11a.

When contrasting perceptual changes for activities held in traditional environments, a couple of interesting observations can be made. Participants questioned in traditional environments were far more likely to already have an interest in science: $70 \%$ of participants surveyed in traditional environments prior to the show considered themselves interested or believing science to be useful. This compares to only $52 \%$ in cathedrals. Post-activity surveys found that participants in non-traditional environments experienced the largest gain in interest level moving to a total of $91 \%$, compared to $88 \%$ of participants in traditional environments. In traditional environments, $9 \%$ of pupils reported they felt particle physics was "useless" prior to the event with this dropping by a single percentage point to $8 \%$ post event. Comparing this to non-traditional and a more distinct shift in attitude is seen with $14 \%$ believing it was "useless" prior to the activity and dropping to $6 \%$ after.

From these observations two hypotheses are proposed. Participants in traditional settings are more likely to already be interested, thus reducing the number of possible perception changes and therefore reducing size 


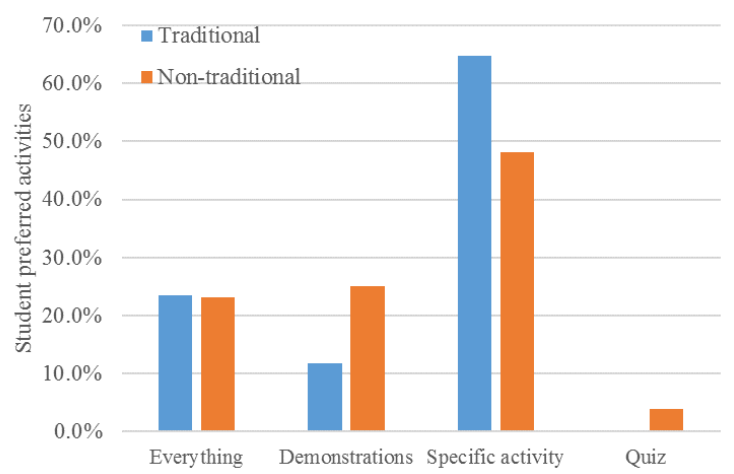

(a)

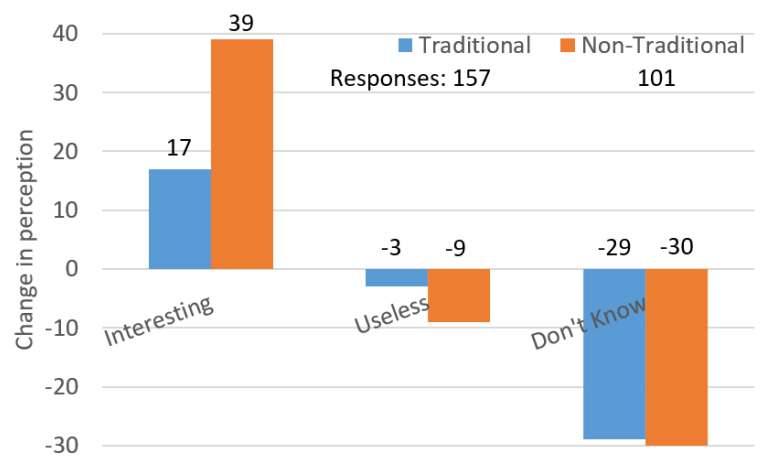

(b)

Figure 11: Contrasting (a) enjoyment of workshop and (b) change of behavior before and after shows for activities, for traditional (blue) and non-traditional (orange) environments. Responses recorded: 379.

of the effective impact that can be had. Participants in traditional environments are less inclined to change their perception towards science if they already believe it to be "useless". A more direct comparison in response can be seen in Figure 11b in which the difference between the prior and post perception is depicted for both environments in absolute numbers. The discontinuity for the traditional environment is the result of participants opting out of the post show online quiz. Fewer responses were recorded for the cathedral events as they were one-off and stand alone events.

Audiences in non-traditional environments are less likely to have interacted with STEM in the past and it is proposed that this results in a more open mind when approached. This in turn means that for events with a focus on knowledge assimilation as well as enjoyment, a more efficient impact can be had. It can be argued though that different audiences (ethnicity, gender, social-economic backgrounds) may respond differently to activities. Appropriate administrative resources are required to carry surveys on larger population sizes for a further study of the effectiveness of working in non-traditional environments.

\section{CONCLUSION}

We have presented two case studies of outreach education programs adapted to work in cathedrals and described practical considerations for pursuing workshops and shows in non-traditional environments. We have outlined details of a table-top activity on the human eye and methods to incorporate evaluation into the activities through quizzes. We have found that the short term impact has been successful in terms of demonstrating assimilation of knowledge, levels of enjoyment and change of attitude. Measuring long-term impact would require significantly more administrative resources and continued cooperation with the external partners. These atypical events have generated further publicity and visibility of activities being carried out at universities, (for e.g. institutional newsletters and blogs) with both audiences internal and external to the university that may not usually be engage with education programs. Our work has motivated the need to standardize the evaluation methods used while engaging with pupils and further incorporate models of working towards best practice.

Further initiatives will be pursued to further address the STEM shortage through teacher training courses and linking industry with educators to address the shortfall in specialist teachers that has been identified as a barrier of entry to STEM. One project being pursued is PHABLABS 4.0 (http://www.phablabs.eu/) to train a larger and better skilled photonics workforce outside of traditional working environments. 


\section{ACKNOWLEDGMENTS}

The authors wish to thank everyone in the Lightwave and Southampton Accelerate! teams, Emma Hart from the Winchester Cathedral learning center, Sally Stewart-Davis from Salisbury Cathedral, and Thomas JeffersonBrain, Mark Burns and Justin Tobias Tsang for helping analyze the data collected in the surveys. The authors acknowledge support from the EPSRC-funded National Hub in High Value Photonic Manufacturing (grant EP/N00762X/1), University of Southampton Physics and Astronomy department, EPSRC-funded Impact Acceleration Account (IAA), IOP Physics Communicators Group, and University of Southampton Student Union for funding researchers taking part in these events; the European Unions Horizon 2020-funded Photonics4all research and innovation program under grant agreement No. 644606 for providing Photonics Explorer kits and outreach tools to disseminate; the OSA, SPIE, IEEE Photonics Society for funding outreach kits.

\section{REFERENCES}

[1] Morgan, R., Kirby, C., and Stamenkovic, A., "The UK STEM Education Landscape." Royal Academy of Engineering, May 2016, http://www.raeng.org.uk/publications/reports/ uk-stem-education-landscape. (Accessed: 7 May 2017).

[2] "Raising Aspirations in Physics: A Review of Research into Barriers to STEM Participation for Students from Disadvantaged Backgrounds." Institute of Physics, 2014, http://www.iop.org/publications/iop/ 2014/file\{_\}64466.pdf. (Accessed: 7 May 2017).

[3] "Concordat for Engaging the Public with Research." Research Council UK, 2017, http://www.rcuk.ac . uk/documents/scisoc/concordatforengagingthepublicwithresearch-pdf/. (Accessed: 1 May 2017).

[4] "About OFFA." Office for Fair Access, 2014, http://www.offa.org.uk/about/. (Accessed: 1 May 2017).

[5] Wong, N. H. L., Posner, M. T., and John, P. V., "The Lightwave Programme and Roadshow : An Overview and Update," in [Proc. SPIE 9793], 97932V, 1-16 (2015).

[6] Wong, N. H. L., Posner, M. T., Mittal, V., Gray, D. R., and John, P. V., "Taking local optics outreach abroad for IYL 2015: administrative and logistical challenges and strategies," in [Proc. SPIE 9946], 99460F (2016).

[7] Bricchi, E., Baggett, J. C., Guilhot, D. A., and Musgrave, I. O., "The lightwave road show," in [Proc. SPIE 9663], 96631L (2003).

[8] Foreman, H. D., Parmigiani, F. R., Roelens, M. A., and Simpson, R. E., "The Lightwave Roadshow," in [Proc. SPIE 9664], 96641U (2005).

[9] "Accelerate!." http://www2.physics.ox.ac.uk/accelerate. (Accessed: 7 May 2017).

[10] "Trends in higher educatio marketing, recruitment and technology." Hanover Research, 2014, http://www . hanoverresearch.com/media/Trends-in-Higher-Education-Marketing-Recruitment-and-Technology- 2 . pdf. (Accessed: 7 May 2017).

[11] Macdonald, A., "Gender Action Guidelines." Photonics 21, 2016, http://phablabs.eu/sites/default/ files/Inventory $\% 20$ of $\% 20$ considerations $\% 20$ to $\% 20$ be $\% 20$ taken $\% 20$ into $\% 20$ account $\% 20$ during $\% 20$ the $\%$ 20design\%20phase_0.pdf. (Accessed: 1 May 2017).

[12] DeWitt, J. and Archer, L., "Who Aspires to a Science Career? A comparison of survey responses from primary and secondary school students," International Journal of Science Education 37(13), 2170-2192 (2015).

[13] "Bringing research to life. University of Southampton Roadshow." http://www.southampton.ac.uk/per/ university/roadshow.page. (Accessed: 7 May 2017).

[14] "Danceroom Spectroscopy." http://www.bristol.ac.uk/research/impact/danceroom-spectroscopy/. (Accessed: 7 May 2017).

[15] Sanmarti-Vila, L., García-Matos, M., Beduini, F., and Carrasco, S., "Collaborative outreach," in [Proc. SPIE 9946], 9946, 99460I (2016).

[16] Posner, M. T., John, P. V., Standen, D., Wheeler, N. V., van Putten, L. D., Soper, N., Parsonage, T., Wong, N. H. L., and Brambilla, G., "Reflecting photonics: Reaching new audiences through new partnerships: IYL 2015 and the Royal Horticultural Society flower show," in [Proc. SPIE 9946], 9946, 994603 (2016). 
[17] "National curriculum in England: science programmes of study - key stages 1 and 2." Department of Education (UK), 2013, https://www.gov.uk/government/uploads/system/uploads/attachment_data/ file/425618/PRIMARY_national_curriculum_-_Science.pdf. (Accessed: 1 May 2017).

[18] "National curriculum in England. Science programmes of study: key stage 3." Department of Education (UK), 2013, https://www.gov.uk/government/uploads/system/uploads/attachment_data/file/ 335174/SECONDARY_national_curriculum_-_Science_220714.pdf. (Accessed: 1 May 2017).

[19] Botting, B., "Statistics for Mission 2014." Archbishops' Council (UK), 2014, https://www . churchofengland.org/media/2432327/2014statisticsformission.pdf. (Accessed: 13 April 2017).

[20] Wong, N. H. L., Tong, A. S. K., Posner, M. T., and Ravagli, A., "Modular and extensible lesson on fiber optics for youths." Proc. SPIE, ETOP (2017). [Accepted]. 